\title{
Compiling sonority scales with obstruent vowels
}

\author{
Matthew Faytak \\ University of California, Berkeley
}

\section{Introduction}

It has been argued that languages systematically license syllabicity to all segment classes more sonorous than the least sonorous syllabic segment in that language (Blevins 1995). ${ }^{1}$ The syllabic segments found in American English, given in Fig. 1, exemplify this arrangement, which results in a contiguous zone of segment classes that can be licensed syllabicity (the permitted nuclei). Since sonority scales have been argued to be ranked with input from acoustic parameters such as intensity (Parker 2008), this could be taken to mean that all languages permit syllabicity in segments falling within a given range for an acoustic parameter. In this paper, I introduce obstruent vowels, phonetic obstruents that behave phonologically as permitted nuclei, and argue that they form a major exception to these generalizations, given their frequent separation from the contiguous range of other permitted nuclei in a given language. The permitted syllabic segments of Bai are also provided in Figure 1 as an example (Dell 1981) of this exceptional pattern.

After a brief overview in Section 2 of the sonority scale for syllabification, as it is canonically compiled, in Section $3.1 \mathrm{I}$ introduce the obstruent vowels. ${ }^{2}$ I

\footnotetext{
${ }^{1}$ For their valuable commentary and feedback, I thank: Sharon Inkelas, Keith Johnson, Larry Hyman, John Ohala, and numerous other commenters at Berkeley's Phonetics and Phonology Phorum. I also thank John Sylak-Glassman for our many ultimately useful discussions. Any errors in interpreting their input are my own.

${ }^{2}$ For lack of dedicated IPA symbols, and given that obstruent vowels are very nearly syllabic voiced fricatives, I will transcribe obstruent vowels as if they were voiced fricatives (e.g. $[\mathrm{y}],[\mathrm{z}]$ ).
} 


\section{Matthew Faytak}

further demonstrate in Section 3 that the phonotactic arrangement shown for Bai in Figure 1 is not uncommon cross-linguistically by presenting a genetically diverse sample of 38 languages with multiple, discontinuous zones of permissible nuclei which include obstruent vowels. Finally, in Section 4, I discuss the implications of obstruent vowels' position in these discontinuous zones for the sonority scale and its compilation as a ranked set of segments: either the sonority scale is purely language-specific and lacks any relation to phonetic substance for at least some languages, or the compilation of sonority scales varies on a language-to-language basis and may take into account extra acoustic parameters such as the presence of prolonged aperiodic noise.

(1) Permitted syllable nuclei in English and Bai (Dell 1981). Classes labeled with "Y(es)" are permitted nuclei; classes labeled with "n(o)" are non-permitted nuclei. Consonant classes absent from a language are not labeled with either.

\begin{tabular}{lllllll} 
Languages & A & R & L & N & S & T \\
\hline \hline Am. English & $\mathbf{Y}$ & $\mathbf{Y}$ & $\mathbf{Y}$ & $\mathbf{Y}$ & $\mathrm{n}$ & $\mathrm{n}$ \\
Bai & $\mathbf{Y}$ & & $\mathrm{n}$ & $\mathrm{n}$ & $\mathbf{Y}$ & $\mathrm{n}$
\end{tabular}

\section{Syllabicity and the sonority scale}

Syllabification is widely said to make reference to the sonority of the individual segments of the input string (Clements 1990, Blevins 1995, Zec 1995). A sonority scale with a fairly fixed ranking of segment classes grounded in phonetic substance is usually assumed to apply for syllabification in all languages, with some languageto-language variation in the rankings of similarly high- or low-sonority segments, i.e. rhotics vs. laterals or fricatives vs. affricates (Jany et al. 2007). Intensity has recently been acknowledged as a good acoustic correlate for higher rank on the sonority scale (Parker 2008, Jany et al. 2007). Figure 2 is a typical representation of this scale, after Blevins (1995), where a capitalized A (for vowels) or a coronal segment in each segment class stands in for the segment class in general, a convention I will use in the remainder of this paper: $\mathrm{R}$ for rhotics, $\mathrm{L}$ for liquids, $\mathrm{N}$ for nasals, $\mathrm{S}$ for fricatives, and $\mathrm{T}$ for stops.

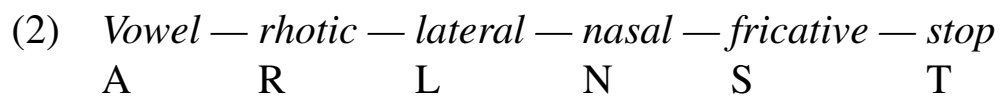

highest sonority $\ldots \ldots \ldots \ldots \ldots \ldots$ lowest sonority

Two generalizations upheld in the literature on sonority and syllabification are relevant for the discussion to follow. The first concerns the varying application of the sonority scale in Figure 2 to syllabification from language to language: languages have a varyingly low sonority threshhold for syllabicity. As noted in Blevins (1995), the upper bound is fixed-non-high vowels are universally permitted nuclei-but the lower bound for permitted nuclei varies from language to language. Despite this variation, Blevins notes, a language's least sonorous possible nucleus always demarcates a boundary above which all segments are possible 
nuclei. Put another way, it appears that languages must license syllabicity to all segments ranked higher on the sonority scale than the lowest-ranked segment (Figure 3 ), dividing the sonority scale into two zones: sufficient sonority and insufficient sonority. Since segments' intensity decreases with lower rank on the sonority scale, this can be taken to represent a cutoff in a parameter or set of parameters for a segment, dubbed "overall sound level" by Parker (2008).

(3) Languages with increasingly low threshholds of syllabicity, after Blevins (1995), except Liangshan Yi data (Li and Ma 1983).

\begin{tabular}{lcccccc} 
Languages & A & R & L & N & S & T \\
\hline \hline Hawai'ian & Y & & $\mathrm{n}$ & $\mathrm{n}$ & $\mathrm{n}$ & $\mathrm{n}$ \\
Sanskrit & Y & Y & $\mathrm{n}$ & $\mathrm{n}$ & $\mathrm{n}$ & $\mathrm{n}$ \\
Lendu & Y & Y & $\mathbf{Y}$ & $\mathrm{n}$ & $\mathrm{n}$ & $\mathrm{n}$ \\
English & Y & Y & Y & $\mathbf{Y}$ & $\mathrm{n}$ & $\mathrm{n}$ \\
Liangshan Yi & $\mathbf{Y}$ & & $\mathbf{Y}$ & $\mathbf{Y}$ & $\mathbf{Y}$ & $\mathrm{n}$ \\
Tashlhiyt Berber & $\mathbf{Y}$ & $\mathbf{Y}$ & $\mathbf{Y}$ & $\mathbf{Y}$ & $\mathbf{Y}$ & $\mathbf{Y}$
\end{tabular}

The second generalization is that non-obstruent segments are assumed to universally outrank obstruent segments on the sonority scale. Zec (1995) makes use of a more granular scale in which vowels are more sonorous than non-obstruent consonants, which are in turn more sonorous than obstruent consonants. Phonetic investigations of a combined seven languages ${ }^{3}$ also show that obstruents are consistently less phonetically intense than non-obstruents (Parker 2008, Jany et al. 2007). These two principles, if taken together, stipulate that if a language licenses syllabicity to obstruents (as do Liangshan Yi and Tashlhiyt), which must be lower-ranked on the scale than sonorants, then all sonorants will be licensed syllabicity. As we will see below, my own investigations show that this is not always the case.

\section{Obstruent vowels as permissible nuclei}

I aim to bring to attention a group of languages which escape the generalizations noted above: despite having obstruent segments (voiced fricatives) in the set of permissible nuclei, these languages fail to license some or all segments from the set of syllabic rhotics, liquids, and nasals. In terms of the generalizations discussed above, this results in extra zones of sufficient sonority not contiguous with the zone containing vowels. It is especially problematic that the non-contiguous zone is populated by an obstruent. Language-specific (re)rankings in the sonority scale are fairly common for certain segment classes, particularly within-category rearrangements of the non-obstruents and the obstruents Jany et al. (2007). The ranking in (4a), where vowels and nasals populate the set of possible nuclei, is particularly common cross-linguistically. We should not expect, however, a ranking as in (4b), where the more rigid ranking of non-obstruents over obstruents is not observed.

${ }^{3}$ English, Spanish, and Cusco Quechua in Parker (2008); Egyptian Arabic, Mongolian, Hindi, and Malayalam in Jany et al. (2007). 
(4)
a. $[A-N]-[R-L-S-T]$
yes
no
b. $[A-S]-[R-L-N-T]$
yes
no

Given the aforementioned fricative segments' unexpected phonological status as possible nuclei and their phonetic obstruent quality, I refer to these segments as obstruent vowels. In this section, I show that obstruent vowels are in fact phonetic obstruents that behave like vowels at a phonological level (Section 3.1), and that the pattern is typologically common in certain language families.

\subsection{Overview of obstruent vowels}

Obstruent vowels are voiced, obstruent segments with characteristics of both voiced fricatives and high vowels. Research on obstruent vowels has been carried out prior to this study, often under a different name than the one used here. The "apical vowels" of the Chinese languages have been examined in articulatory, acoustic, and perceptual terms for standard and Beijing Mandarin (Yu 1999, Cheung 2004, Lee 2005) as well as Suzhou (Feng 2007). The "fricative vowels" of Bantoid languages in western Africa are rarely but increasingly a subject of study (Connell 2007).

Obstruent vowels are very similar to voiced fricatives. Articulatorily, their tongue body position resembles a high, slightly lax vowel, central or front (Lee 2005, Feng 2007), except for an added constriction of one of two types: coronal (raised tongue tip or blade) or labiodental (lower lip raised to upper teeth). Coronal articulations range from alveolar to post-alveolar or retroflex, and a secondary articulation of lip rounding or protrusion is rarely attested (e.g. Feng (2007)). Constrictions significantly narrow the aperture of the airway; this is visible when the vowel is labiodental, and has been confirmed instrumentally for coronals (Feng 2007). The narrow aperture translates to turbulent airflow in most productions; fricative noise occurs in frequency bands consistent with the location of the obstruent constriction. Some formant structure is usually visible, although higher formant structure is almost always obscured by fricative noise.

Put another way, obstruent vowels are very nearly syllabic voiced fricatives. The primary distinction between an obstruent vowel and a voiced fricative at the level of phonetics is that obstruent vowels tend to lose some turbulence towards the end of their production. This non-obstruent portion is phonologically inert and usually realized as a central, mid-high vowel colored by carryover of the position of the tongue tip or lips from the obstruent portion. This generalization does paper over some variation in the category: the duration and intensity of turbulence varies widely from production to production and language to language.

Another major distinction between obstruent vowels and voiced fricatives lies at the level of phonology: obstruent vowels pattern as phonological vowels. In Kom, for instance, the two obstruent vowels / v z/ pattern as [-low] vowels with different [ \pm front] specifications in vowel coalescence processes (Faytak 2013). Futher- 
more, in all languages surveyed in the next section, most contrastive suprasegmentals (tones, phonation) occur on obstruent vowels. ${ }^{4}$ Obstruent vowels may also be obligatory nuclei, which must be realized with syllabic prominence (Blevins 1995). In Bai, for instance, the segment / $/$ only occurs as the nucleus $[\mathrm{y}]$; there is no corresponding non-syllabic initial [v-] (Dell 1981).

\subsection{Discontinuous zones of permitted nuclei}

Recall the patterning of permitted nuclei along a canonical sonority scale, given in (3). A significant number, but not all, languages that have obstruent vowels include these syllabic voiced fricatives in the set of permitted nuclei while excluding some or all non-obstruent segments, creating multiple zones of non-permitted nuclei, as schematized in (5). Certain languages described with obstruent vowels, such as Shanghai, do not prove to be problematic, since all permitted segments form a contiguous range, but languages like Limbum and Bai fail to permit some number of non-obstruent segments.

(5) Occurrence of various non-vocalic syllabic nuclei in four languages, after Blevins (1995). Shanghai data from Zhu (2006); Limbum data from Fransen (1995); Bai data from Dell (1981).

\begin{tabular}{|c|c|c|c|c|c|c|}
\hline \multirow[t]{2}{*}{ Shanghai } & {$[\mathrm{A}$} & & $\mathrm{L}$ & $\mathrm{N}$ & $\mathrm{S}]$ & {$[\mathrm{T}]$} \\
\hline & [pū] 'step' & & [1] 'ear' & {$[\bar{y}]$ 'five' } & {$[\overline{\mathrm{z}}]$ 'tree' } & no \\
\hline \multirow[t]{2}{*}{ Limbum } & {$[\mathrm{A}]$} & {$[\mathrm{R}$} & L] & {$[\mathrm{N}$} & $\mathrm{S}]$ & [T] \\
\hline & [tō] 'hole' & no & no & [m̄tá:r] 'thirty' & {$\left[{ }^{\mathrm{g}} \mathrm{g} \overline{\mathrm{v}} \mathrm{p}\right]$ 'fowl' } & no \\
\hline \multirow[t]{2}{*}{ Bai } & {$[\mathrm{A}]$} & & {$[\mathrm{L}$} & $\mathrm{N}]$ & {$[\mathrm{S}]$} & [T] \\
\hline & {$\left[\mathrm{ts}^{\mathrm{h}} \mathrm{a}^{44}\right]$ 'sing' } & & no & no & {$\left[1 v^{33}\right]$ 'green' } & no \\
\hline
\end{tabular}

Here, I introduce a sample of languages, compiled primarily from these two families, which make use of obstruent vowels. The heavy skewing of the sample toward Niger-Congo and Sino-Tibetan languages (6) was not the result of a targeted search within these families but rather emerged from a brute-force search of the available phonetic and phonlogical descriptive literature for all languages: the arrangement seen in Limbum and Bai is fairly common within several language families, namely the Sino-Tibetan and Niger-Congo languages, but not elsewhere. The sample plainly shows that although restricted in distribution by genetic grouping cross-linguistically, obstruent vowels are very common as members of discontinuous zones of permitted nuclei in the languages where they are found, and this arrangement is stable enough to be present in a large number of languages.

${ }^{4}$ The exception is nasalization, which may not occur on obstruent vowels at all, given that nasalization is antagonistic to achieving turbulent airflow (Yu 1999). 
(6) Sample of obstruent-vowel-having languages with sources, arranged by genetic subgrouping.

\begin{tabular}{|c|c|c|c|}
\hline \multicolumn{4}{|c|}{ Tibeto-Burm. (13) } \\
\hline Bai & Dell (1981) & Lahu & Matisoff (1973) \\
\hline Cuona & Sun et al. (1991) & Lüsu & Sun et al. (1991) \\
\hline Ergong & Sun et al. (1991) & Naxi & He and Jiang (1985) \\
\hline Ersu & Sun et al. (1991) & Nusu & Sun et al. (1991) \\
\hline Gazhuo & Sun et al. (1991) & Trung & Sun et al. (1991) \\
\hline Hani & Namkung (1996) & Tshangla & Sun et al. (1991) \\
\hline Idu & Sun et al. (1991) & & \\
\hline \multicolumn{4}{|l|}{ Sinitic (12) } \\
\hline Changsha & $\mathrm{Wu}(2005)$ & Pingyao & Hou (1980) \\
\hline Jixi & Zhao (1989) & Suzhou & Qian (1992) \\
\hline Liantang & Deng (1996) & Wenzhou & You and Yang (1998) \\
\hline Loudi & Yan and Liu (1998) & Wuning & Sagart (1993) \\
\hline Mandarin & Duanmu (2000) & Yangzhou & Li et al. (1996) \\
\hline Meixian & Hashimoto (1973) & Xining & Li and Zhang (1994) \\
\hline \multicolumn{4}{|c|}{ Niger-Congo (5) } \\
\hline Dschang & Bird (1997) & Len & Connell (2007) \\
\hline Ekajuk & Crabb (1965) & Limbum & Fransen (1995) \\
\hline Kom & Faytak (2013) & & \\
\hline \multicolumn{4}{|l|}{ Hmongic (4) } \\
\hline DNS Hm. & Niederer (1998) & DSJ Hm. & Niederer (1998) \\
\hline LBH Hm. & Niederer (1998) & TS Hm. & Niederer (1998) \\
\hline \multicolumn{4}{|l|}{ Altaic (2) } \\
\hline Mangghuer & Dwyer (2008) & Santa & Kim (2003) \\
\hline \multicolumn{4}{|l|}{ Japonic (2) } \\
\hline$\overline{\text { O. Miyako }}$ & Pellard (2009) & M. Ishigaki & Izyuama (2003) \\
\hline
\end{tabular}

The sample in (6) was compiled with maximum genetic-linguistic diversity in mind. Since the overwhelming majority of the languages examined come from Sino-Tibetan and Niger-Congo, however, I appeal to subgrouping within these families to maximally distribute the sample among as much genetic diversity as possible. Sino-Tibetan subgrouping was aided by use of the classification in Namkung (1996); no more than four languages were selected from any one of Namkung's Tibeto-Burman subgroupings. In other families, data tends to be sparser, and essentially any data that could be found regardless of subgrouping was selected. Fortuitously, there is little genetic proximity elsewhere in the sample, with a few exceptions. $^{5}$

5 The four Hmongic languages are taken from the closely related Chuanqiandian "dialect cluster" (Niederer 1998); and the two Ryukyuan languages are fairly closely related (Bentley 2008). In both cases, however, the phonotactics of obstruent vowels in these languages are distinct enough even from their close relatives to merit inclusion in the sample. 
The 38 languages of the sample were examined and their permitted and impossible nuclei noted. Some special considerations must be noted: marginal (often paralinguistic) use of nasals as nuclei is broadly present in the Sinitic languages. I count these cases as non-permitted but mark them with an asterisk $\left(^{*}\right)$ in the figures below. Rhotic and nasal vowels are frequently present in Tibeto-Burman and Sinitic; I do not count these as syllabic rhotics or nasals. ${ }^{6}$

(7) Patterns of syllabicity licencing in the 38 languages of the sample in (6). Asterisk (*) indicates marginal syllabification of a segment class, which is counted as non-permitted.

\begin{tabular}{|c|c|c|c|c|c|c|}
\hline Languages & A & $\mathrm{R}$ & $\mathrm{L}$ & $\mathrm{N}$ & $S$ & $\mathrm{~T}$ \\
\hline \multicolumn{7}{|l|}{ Gap $\geq 2: 23$} \\
\hline Cuona, Trung, Tshangla, Santa & $\overline{\bar{Y}}$ & $\overline{\mathrm{n}}$ & $\overline{\mathrm{n}}$ & $\overline{\mathrm{n}}$ & $\overline{\bar{Y}}$ & $\overline{\mathrm{n}}$ \\
\hline Mandarin, Yangzhou & $\mathbf{Y}$ & $\mathrm{n}$ & $\mathrm{n}$ & $*$ & $\mathbf{Y}$ & $\mathrm{n}$ \\
\hline Ersu, Idu, Limbum, Naxi, Nusu & $\mathbf{Y}$ & $\mathrm{n}$ & $\mathrm{n}$ & $\mathbf{Y}$ & $\mathbf{Y}$ & $\mathrm{n}$ \\
\hline $\begin{array}{l}\text { Bai, Ergong, Hani, Len, } \\
\text { Pingyao, all Hmong, Lahu }\end{array}$ & $\mathbf{Y}$ & & $\mathrm{n}$ & $\mathrm{n}$ & $\mathbf{Y}$ & $\mathrm{n}$ \\
\hline Minhe Mangghuer & $\mathbf{Y}$ & $\mathbf{Y}$ & $\mathrm{n}$ & $\mathrm{n}$ & $\mathbf{Y}$ & $\mathrm{n}$ \\
\hline Changsha & $\mathbf{Y}$ & & $\mathrm{n}$ & $*$ & $\mathbf{Y}$ & $\mathrm{n}$ \\
\hline \multicolumn{7}{|l|}{ Gap = 1: 15} \\
\hline $\begin{array}{l}\text { Dschang, Ekajuk, Gazhuo, } \\
\text { Ishgaki, Liantang, Loudi, Lüsu, } \\
\text { Ōgami, Meixian, Suzhou, } \\
\text { Wenzhou, Wuning, Yudu }\end{array}$ & $\mathbf{Y}$ & & $\overline{\mathrm{n}}$ & $\overline{\mathbf{Y}}$ & $\overline{\mathbf{Y}}$ & $\bar{n}$ \\
\hline Jixi & $\mathbf{Y}$ & & & $*$ & $\mathbf{Y}$ & $\mathrm{n}$ \\
\hline Xining & $\mathbf{Y}$ & & $\mathbf{Y}$ & $*$ & $\mathbf{Y}$ & $\mathrm{n}$ \\
\hline
\end{tabular}

The results are provided in (7). Ranges of permitted and non-permitted nuclei are delinated by square brackets containing "yes" and "no" respectively; asterisks indicate marginally permitted nuclei. The results can be divided into two groups: languages where the gap between the two zones of permitted nuclei comprises two or more segment classes, and languages where the gap comprises one segment class. Perhaps surprisingly, the majority of the sample (23 languages) exhibits a large gap $(\geq 2)$ between permitted nuclei zones; furthermore, if marginally permitted nuclei are excluded, nearly half of the sample (18 languages) has only vowels and fricatives as permitted nuclei.

\section{Conclusion: Implications for the sonority scale(s)}

Since the arrangement of the sonority scale is in a sense intended to reflect phoneticsarranging segments by Parker (2008)'s “overall sound level," for instance-a sim-

${ }^{6}$ One might object that obstruent vowels are counted as obstruents in this schema, but that rhotic and nasal vowels are not counted as rhotics or nasals. As noted previously, however, obstruent vowels are essentially voiced fricatives, with an obstruent manner of articulation, while nasal or rhotic vowels are not (respectively) nasal stops or rhotic approximants. 


\section{Matthew Faytak}

ple two-way division of segments into permitted and non-permitted nuclei suggests that one parameter or a closely related set of parameters working in conjunction distinguishes, for a given language, the threshhold below which a segment is not a permitted nucleus (see Language A in Figure 8 below). For many obstruentvowel-having languages, then, the sonority scale is not effective: in its compilation, segments are ranked (and then selected as permitted or non-permitted nuclei) based on the value of some acoustic parameter(s), but the acoustic parameters which are typically used as input ("overall sound level" or intensity) fail to line up all segments such that the observed permitted and non-permitted nuclei match with the predicted permitted and non-permitted nuclei. Rhotics, liquids, and nasals, in particular, should serve as permitted nuclei if all nuclei with a sufficiently high overall sound level are permitted (Language B in Figure 8).

(8) Permitted and non-permitted nuclei as determined (or not determined) by a cutoff in the value for "overall sound level": for Language A, a clear cutoff value of 70 applies, but no such clear critical value emerges for Language B. Sound level values are ad hoc but are intended to reflect Parker (2008)'s overall sound level measurements.

\begin{tabular}{rcccccc} 
Languages & $\mathrm{A}$ & $\mathrm{R}$ & $\mathrm{L}$ & $\mathrm{N}$ & $\mathrm{S}$ & $\mathrm{T}$ \\
\hline \hline Lang. A & $\mathbf{Y}$ & $\mathbf{Y}$ & $\mathbf{Y}$ & $\mathbf{Y}$ & $\mathrm{n}$ & $\mathrm{n}$ \\
Sound level & 100 & 90 & 80 & 70 & 50 & 10 \\
Lang. B & $\mathbf{Y}$ & $\mathrm{n}$ & $\mathrm{n}$ & $\mathrm{n}$ & $\mathbf{Y}$ & $\mathrm{n}$ \\
Sound level & 100 & 90 & 80 & 70 & 50 & 10
\end{tabular}

Given that the problem appears to lie with the choice of acoustic parameters, one possible solution is to completely discard acoustic parameters as a ranking condition for the sonority scale in at least some cases. It is possible, as has been shown in Section 3.1, that obstruent vowels are phonologically vowels rather than voiced fricatives. It could be argued that for these languages, the sonority scale is a purely logical scale in the sense Mortensen (2006), or a scale whose arrangement reflects a formerly substantively grounded order that has persisted despite the loss, due to sound change, of its substantive grounding. The increase in the typological markedness of the sets of permitted nuclei is then simply maintenance of logical relationships among realizations of a vowel phoneme (in the case of Mandarin, identity). Diachrony supports this analysis in some better-documented cases: often, obstruent vowels' origins can be traced back to assimilation of high vowels to syllable-initial fricatives and affricates, as is the case with many descendants of Middle Chinese Chen (1976). In other languages, including in standard Mandarin, this allophonic realization of historically underlying high vowels as obstruent vowels (in Mandarin, $/ \mathrm{i} />[\mathrm{z}],[\mathrm{z}])$ is the sole source of obstruent vowels synchronically.

I prefer a solution that factors in continuous aperiodic noise as part of the overall salience of a segment. While purely logical scales do offer a solution to the ranking problem, they also completely remove acoustic parameters as a factor, despite a 
Compiling sonority scales with obstruent vowels

substantial amount of research that suggests a close correlation of sonority and acoustic parameters. They also do not motivate the fairly frequent appearance of obstruent vowels in discontinuous zones of permitted nuclei, frequently without any other non-vocalic segments joining them. Rather than remove acoustic parameters, I propose that an additive approach be taken: that the languages scrutinized in this paper make reference to additional acoustic parameters not typically thought to be involved in raking segments along the sonority scale. One parameter in particular stands out as characteristic of fricatives: continuous turbulent airflow that results in salient, continuous aperiodic noise.

Further work is needed to see how, precisely, the extra parameter of continuous noise might be factored into the calculation of sonority ranking. One possibility that ought to be investigated further is a conjunction of scales for ranking a domain-specific scale (here, sonority for purposes of syllabification); a mechanism of conjunction is used in Optimality Theory to create complex, domain-specific constraints from simpler, broader ones (Moreton and Smolensky 2002). An analogous mechanism would allow the creation of a more finely tuned sonority scale from two less precise ones: a language that handles sonority similarly to Bai could be generated, where only the set of segments having the most intense periodic sound or the most intense aperiodic sound are permitted nuclei. The formal statement of such a mechanism, however, is beyond the scope of this research.

\section{References}

Bentley, J.R., 2008. A linguistic history of the forgotten islands: a reconstruction of the proto-language of the Southern Ryūkyūs. Global Oriental.

Bird, Steven, 1997. Dschang syllable structure. In Harry van der Hulst and Nancy Ritter, eds., The Syllable: Views and Facts, 447-476. Oxford University Press.

Blevins, Juliette, 1995. The Syllable in Phonological Theory. In J. Goldsmith, ed., The Handbook of Phonological Theory, 206-244. Blackwell.

Chen, Matthew Y., 1976. From Middle Chinese to Modern Peking. Journal of Chinese Linguistics 4(2):113-277.

Cheung, Yuk Man, 2004. A perceptual analysis of the apical vowels in Beijing Mandarin. Master's thesis, City University of Hong Kong.

Clements, George N., 1990. The role of the sonority cycle in core syllabification. In John Kingston and Mary E. Beckman, eds., Papers in Laboratory Phonology: Volume 1, Between the Grammar and Physics of Speech, 283-333. Cambridge University Press.

Connell, Bruce, 2007. Mambila fricative vowels and Bantu spirantization. Africana Linguistica 13:7-31.

Crabb, David W., 1965. Ekoid Bantu languages of Ogoja, Eastern Nigeria, Part 1: Introduction, phonology and comparative vocabulary. Cambridge.

Dell, François, 1981. La langue bai: phonologie et lexique. Ecoles des Hautes 


\section{Matthew Faytak}

Etudes en Sciences Sociales, Paris.

Deng, Y., 1996. Guangxi He Xian (Liantang) Kejia hua yinxi [The sound system of Guangxi He County (Liantang) Hakka]. Fangyan 4.

Duanmu, San, 2000. Phonology of Standard Chinese. Oxford.

Dwyer, Arienne, 2008. Tonogenesis in Southeastern Monguor. In K. Harrison and D. Rood, eds., Lessons from documented endangered languages, 111-128. John Benjamins.

Faytak, Matthew, 2013. Obstruent vowels in Kom. Unpublished ms., University of California, Berkeley.

Feng, Ling, 2007. The articulatory and acoustic study of fricative vowels in Suzhou Chinese. In Proceedings of ICPhS XVI.

Fransen, Margo A.E., 1995. A grammar of Limbum: a Grassfields Bantu language spoken in the North-West Province of Cameroon. Ph.D. thesis, Vrije Universiteit te Amsterdam.

Hashimoto, Mantaro, 1973. The Hakka Dialect. Cambridge.

He, Jiren and Jiang, Zhuyi, 1985. Naxiyu jianzhi [Brief description of the Naxi language]. Minzu chubanshe [Nationalities Press].

Hou, Jingyi, 1980. Pingyao fangyan de liandu yinbiao [Tone sandhi in the Pingyao dialect]. Fangyan 1.

Izyuama, Atsuko, 2003. The Grammar of Ishigaki Miyara Dialect in Luchuan. In A. Izyuama, ed., Studies on Luchuan Grammar. Endangered Languages of the Pacific Rim Series A4-024, Nakanishi Printing Co.

Jany, C., Gordon, M., Nash, C.M., and Takara, N., 2007. How universal is the sonority hierarchy?: A cross-linguistic acoustic study. In Proceedings of ICPhS $X V I$.

Kim, Steven S., 2003. Santa. In J. Janhunen, ed., The Mongolic Languages, 346363. Routledge.

Lee, Wai-Sum, 2005. The articulatory and acoustical characteristics of the "apical vowels" in Beijing Mandarin. Journal of the Acoustical Society of America 118(3.2).

Li, Min and Ma, Ming, 1983. Liangshan Yiyu yuyin gailun [Introduction to the sounds of the Liangshan Yi language]. Sichuan minzu chubanshe [Sichuan Nationalities Press].

Li, Rong, Wang, Shihua, and Huang, Jilin, 1996. Yangzhou fangyan cidian [Dictionary of the Yangzhou dialect]. Jiangsu jiaoyu chubanshe [Jiangsu Education Press].

Li, Rong and Zhang, Chengcai, 1994. Xining fangyan cidian [Dictionary of the Xining dialect]. Jiangsu jiaoyu chubanshe [Jiangsu Education Press].

Matisoff, James A., 1973. The grammar of Lahu. University of California Press.

Moreton, E. and Smolensky, P., 2002. Typological consequences of local constraint conjunction. In Proceedings of WCCFL 21, 306-319.

Mortensen, David R., 2006. Logical and substantive scales in phonology. Ph.D. thesis, University of California, Berkeley. 
Compiling sonority scales with obstruent vowels

Namkung, Ju, 1996. Phonological inventories of Tibeto-Burman languages. STEDT, Center for Southeast Asia Studies, University of California.

Niederer, Barbara, 1998. Les langues Hmong-Mien (Miao-Yao): Phonologie historique. LINCOM Europa.

Parker, Steven, 2008. Sound level protrusions as physical correlates of sonority. Journal of Phonetics 36(1):55-90.

Pellard, T., 2009. Ōgami-Éléments de description d'un parler du Sud des Ryūkyū. Ph.D. thesis, Ecole des Hautes Etudes en Sciences Sociales.

Qian, Nairong, 1992. Dangdai Wuyu yanjiu [Contemporary studies in Wu languages]. Shanghai jiaoyu chubanshe [Shanghai Education Press].

Sagart, Laurent, 1993. Les dialectes gan: études sur la phonologie et le lexique d'un groupe de dialectes chinois. Langages croisés.

Sun, Hongkai et al., 1991. Zangmianyu yuyin he cihui [Phonologies and Vocabularies of Tibeto-Burman Languages]. Zhongguo shehui kexue chubanshe [China Social Sciences Press].

$\mathrm{Wu}$, Yunji, 2005. A synchronic and diachronic study of the grammar of the Chinese Xiang dialects. Walter de Gruyter.

Yan, Qinghui and Liu, Lihua, 1998. Loudi fangyan cidian [Dictionary of the Loudi dialect]. Jiangsu jiaoyu chubanshe [Jiangsu Education Press].

You, Rujie and Yang, Qianming, 1998. Wenzhou fangyan cidian [Dictionary of the Wenzhou dialect]. Jiangsu jiaoyu chubanshe [Jiangsu Education Press].

Yu, A. C.L., 1999. Aerodynamic constraints on sound change: The case of syllabic sibilants. In Proceedings of ICPhS XIV.

Zec, Draga, 1995. Sonority constraints on syllable structure. Phonology 12(1):85129.

Zhao, Rixin, 1989. Anhui Jixi fangyan yinxi tedian [Special characteristics of the sound system of the Anhui Jixi dialect]. Fangyan 2.

Zhu, Xiaonong, 2006. A grammar of Shanghai Wu. LINCOM Europa.

Matthew Faytak

Department of Linguistics

University of California, Berkeley

1203 Dwinelle Hall, Berkeley, CA 94720-2650

mf@berkeley.edu 